\title{
How (Many) Descriptive Claims About Political Polarization Exacerbate Polarization
}

\author{
Uwe Peters $^{\text {abc }}$ \\ [a] Department of Psychology, King's College London, London, United Kingdom. [b] Center for Science and Thought, University of Bonn, Bonn, Germany. \\ [c] Leverhulme Centre for the Future of Intelligence, University of Cambridge, Cambridge, United Kingdom.
}

Journal of Social and Political Psychology, 2021, Vol. 9(1), 24-36, https://doi.org/10.5964/jspp.5543

Received: 2020-06-28 • Accepted: 2020-10-09 • Published (VoR): 2021-02-19

Handling Editor: J. Christopher Cohrs, Philipps University Marburg, Marburg, Germany

Corresponding Author: Uwe Peters, Department of Psychology, King's College London, De Crespigny Park Camberwell, London SE5 8AB, UK. E-mail: u.peters@kcl.ac.uk

\begin{abstract}
Recently, researchers and reporters have made a wide range of claims about the distribution, nature, and societal impact of political polarization. Here I offer reasons to believe that even when they are correct and prima facie merely descriptive, many of these claims have the highly negative side effect of increasing political polarization. This is because of the interplay of two factors that have so far been neglected in the work on political polarization, namely that (1) people tend to conform to descriptive norms (i.e., norms capturing [perceptions of] what others commonly do, think, or feel), and that (2) claims about political polarization often convey such norms. Many of these claims thus incline people to behave, cognize, and be affectively disposed in ways that contribute to social division. But there is a silver lining. People's tendency to conform to descriptive norms also provides the basis for developing new, experimentally testable strategies for counteracting political polarization. I outline three.
\end{abstract}

\section{Keywords}

political polarization, polarization claims, descriptive norms

"I am whatever you say I am. [...] In the paper, the news, every day I am." (Eminem)

In the wake of tense public debates on Trump's presidency, 'Brexit', the rise of populist parties, climate change, COVID-19 restrictions, and many other hot-button issues, political polarization has become an important topic in psychological, political, and interdisciplinary research (Hart, Chinn, \& Soroka, 2020; Iyengar \& Massey, 2019; Maher, Igou, \& van Tilburg, 2018; Mason, 2018a; Nisbet, Cooper, \& Garrett, 2015; Talisse, 2019). In research publications and media reports on political polarization especially in the U.S. and Europe, claims such as the following are common: 
Table 1

A Selection of Recent Polarization Claims

(1) "Political polarization [in the U.S. and Europe] is on the rise." (Maher et al., 2018, p. 205)

(2) "Ordinary Americans increasingly dislike and distrust those from the other party." (Iyengar et al., 2019, p. 129)

(3) "European elections expose polarized British public." (Shackle, 2019, p. 1)

(4) "U.S. liberals and conservatives not only disagree on policy issues: they are also increasingly unwilling to live near each other, be friends, or get married to members of the other group." (Brick \& van der Linden, 2018, p. 2)

(5) "[A]ffective [political] polarization is acutely present in European party systems, as partisans are often extremely hostile towards competing parties." (Reiljan, 2020, p. 1)

(6) "U.S. citizens are more inclined than ever to regard the ideas of their political opponents as not only misguided, but as a significant threat to the well-being of the nation; they are also more likely to regard citizens who affiliate with an opposition party as unintelligent, dishonest, and immoral." (Talisse, 2019, p. 95)

(7) "90\% [U.S. Americans] believe their country is divided over politics and $60 \%$ feel pessimistic about their country overcoming these divisions." (Heltzel \& Laurin, 2020, p. 179)

The statements in Table 1 and indeed just a brief Google search on political polarization indicate that researchers and reporters writing on the topic tend to agree that especially in the U.S. and (Western) Europe political polarization is widespread and/or widely perceived to be so (Carothers \& O’Donohue, 2019; Iyengar et al., 2019; Klar, Krupnikov, \& Ryan, 2019; Maher et al., 2018). Researchers also typically concur that while it might in some cases be rational or even beneficial (Becker et al., 2019; Shi et al., 2019), overall, political polarization is ethically, epistemically, and politically problematic (Iyengar et al., 2019; Talisse, 2019). It is, for instance, thought to lead people into political 'echo chambers' that make them more extreme in their views (Sunstein, 2009), susceptible to 'fake news' (Iyengar \& Massey, 2019), reluctant to accept science (Nisbet, Cooper, \& Garrett, 2015), and unwilling to respect their political opponents as equals (McCoy, Tahmina, \& Somer, 2018). This may contribute to political deadlock in policy-making on some of the most pressing issues of our time (e.g., climate change; Van Boven, Ehret, \& Sherman, 2018). As Talisse (2019) puts it (with focus on the U.S.),

politics is more divisive than ever, and severe political divisions are undermining democracy. Ironically, that's the one thing upon which everybody seems to agree. Lamentations over our political divides are commonly accompanied by related warnings concerning political 'bubbles,' 'silos', and 'echo chambers'; these are said to produce 'intellectual closure,' 'groupthink,' 'spin,' 'derp,' 'post-truth,' and forms of 'derangement.' (p. 95)

In the following, I will largely set aside whether such 'lamentations' and the kind of claims about political polarization illustrated in Table 1 are accurate. Instead, I want to focus on an issue related to them: What social effects might such written or oral, possibly correct and prima facie merely descriptive statements about political polarization by researchers or reporters have on an audience?

I shall offer reasons to believe that many of these statements - henceforth 'polarization claims' - fuel political polarization. This is because of the interplay of two factors that have so far been neglected in the work on political polarization, namely that (1) people tend to conform to descriptive norms, i.e., norms capturing (perceptions of) what others commonly do, think, or feel (Cialdini, 2003, p. 105; Prentice, 2007, p. 629), and that (2) polarization claims often communicate such norms. Due to the interplay of (1) and (2), many polarization claims incline those receiving them to behave, cognize, and be affectively disposed in ways that increase social division. There is, however, also a constructive side to it: People's tendency to conform to descriptive norms also provides the basis for developing hitherto 
unexplored, experimentally testable strategies for counteracting political polarization. I outline three. They are, just as the overall argument of this paper, indirectly supported by an extrapolation from studies on descriptive norms about phenomena other than political polarization. So far, there are no studies on descriptive norms directly testing the effects of polarization claims. This paper is intended to stimulate social and political psychologists to start empirically investigating the connections between political polarization, polarization claims, and descriptive norms.

\section{The Relevant Type of Political Polarization}

When it comes to the concept of political polarization, psychologists and political scientists distinguish between "affective polarization" and "ideological polarization" (Iyengar et al., 2019; Mason, 2018b; Webster \& Abramowitz, 2017). Affective polarization refers to people's aversive feelings, dislike, and distrust toward others with the opposite political orientation (Webster \& Abramowitz, 2017). Interestingly, studies suggest that affective polarization is only inconsistently grounded in policy-related attitudes (Mason, 2018b). For instance, U.S. Democrats and Republicans have been found to dislike and distrust their political opponents as persons while in fact not disagreeing much with them over substantive policy issues (e.g., abortion or gun control) (Iyengar et al., 2019; Mason, 2018b). Affective polarization is thus distinct from ideological polarization, i.e., the division between political opponents with respect to their policy-related views (but the latter might feed into the former, see Webster \& Abramowitz, 2017).

I will here focus on affective polarization. This is because it strikes me as particularly socially detrimental. After all, mutual dislike and distrust among political opponents reduce their willingness to search for compromises on, for instance, policy issues thus undermining any potential bridge over ideological divides. Mutual antipathy among political opponents is also particularly likely to increase the "sorting" of society into politically homogenous groups, creating fertile breeding ground for group polarization (Bishop, 2009; Mason, 2018a; Talisse, 2019), which occurs when like-minded members of a deliberating group move toward a more extreme viewpoint in whatever direction is indicated by their pre-deliberation tendency (Sunstein, 2009). Affective polarization is thus especially important to tackle. It will occupy center stage in the discussion here. ${ }^{1}$ In the rest of the paper, the term 'political polarization' will refer primarily to affective polarization.

\section{Characterizing Polarization Claims}

In the debate on political polarization, polarization claims are common. To clearly specify these claims (as I understand them here), they have the following five key features that will become relevant below.

First, polarization claims tend to be or are perceived as authoritative and are readily endorsed by the audience. They include statements by researchers with the relevant expertise (e.g., political psychologists), informed non-experts (e.g., BBC science reporters), and credible academic experts with less relevant expertise (see also "expert trespassing testimony"; Gerken, 2018, p. 299). Relatedly, these claims can be found within academia, for instance, in journal articles, but also in the media, TV, newspapers, and so on.

Second, polarization claims might be about the de facto distribution of political polarization, or about people's perceptions of (i.e., their beliefs about) it (e.g., "90\% U.S. Americans believe their country is divided over politics"; Heltzel \& Laurin, 2020, p. 179). These perceptions might be accurate or inaccurate.

Third, notice that polarization claims generally ascribe socially problematic features to people. As illustrated in Table 1, they attribute, for instance, the property of being polarized, distrustful, unwilling to be friends with political opponents, etc. to members of a social group.

1) Having said that, many points I will make below can be extended to ideological polarization. It is, however, not obvious that this applies to all of them. For instance, data by Levendusky and Malhotra (2016a) suggest that there are important differences. Assessing these differences is an interesting open question for future research. 
Fourth, polarization claims often involve broad generalizations about groups (e.g., people in the U.S./Europe, liberals, partisans, Republicans, etc.) either without explicit quantifiers (e.g., 'some') or with wide-scope quantifiers (e.g., 'most') or $>50 \%$ percentiles to describe the reference class. When they do not involve explicit quantifiers, they capture principled assertions about a social category as a whole (e.g., people in the U.S./Europe, 'ordinary Americans', etc.). Importantly, studies found that people tend to construe statements referring to whole social categories strongly as conveying that (almost) all members of the category display the feature at issue (Cimpian, Brandone, \& Gelman, 2010). Hence, polarization claims often communicate that most members of a given group display certain properties. I shall call this feature of these claims genericity.

Finally, polarization claims tend to invoke a temporal dynamic: 'political polarization in the U.S. and Europe is on the rise', 'ordinary Americans increasingly dislike and distrust those from the other party', etc. indicate that polarization is becoming more prevalent. I shall call this feature of many polarization claims dynamicity. Some polarization claims involve a static framing (e.g., 'Affective polarization is acutely present in European party systems.'). But since various studies are taken to show that political polarization is in fact increasing, many polarization claims do display dynamicity (for examples, see Iyengar et al., 2019). Below I argue that given their genericity and dynamicity, polarization claims communicate a particular kind of social norms to an audience. The next section introduces these norms.

\section{Descriptive Norms}

In psychological work on social norms, researchers distinguish between prescriptive (or injunctive) norms, which capture (perceptions of) what 'ought' to be the case or to be done, and descriptive norms, which capture (perceptions of) what people in a particular group commonly do, think, or feel (Cialdini, 2003, p. 105; Prentice, 2007). ${ }^{2}$ Examples of prescriptive norms would be that people should love their neighbors, or that politicians should be honest. Examples of descriptive norms would be that bakers get up early, or that most students are on social media. ${ }^{3}$ Both types of norms can influence people's behavior. Descriptive norms are thought to motivate by "providing evidence as to what will likely be effective and adaptive action", the underlying rationale being that if most members of a group are doing it, it must be a sensible thing (in the group) to do as they do (Cialdini et al., 1990, p. 1015).

There is much evidence that people often conform in their behavior and cognition to descriptive norms when they learn about them. For instance, studies (including many field experiments) found that when told that a majority of others do so, many people are more likely to increase (or reduce - depending on the majority's response) their own energy consumption, littering, recycling, water conservation (Goldstein et al., 2008; Lede \& Meleady, 2019; Mortensen et al., 2019; Schultz et al., 2007), tax paying (Hallsworth et al., 2017), acceptance of an employment decision (Coffman et al., 2017), voting turnout during elections (Gerber \& Rogers, 2009), healthy eating (Staunton et al., 2014), use of stereotypes (Duguid \& Thomas-Hunt, 2015), display of corrupt behavior (Köbis et al., 2015), and even willingness to steal (Cialdini et al., 2006). There is some evidence that people often conform to descriptive norms about others' behavior even when they do not politically identify with these others (e.g., a Democrat being inclined to act in ways popular amongst Republicans), suggesting that a "general desire to conform" to descriptive norms and others may even "out-power the common in-group vs. out-group mentality" (Pryor, Perfors, \& Howe, 2019, p. 1).

Additionally, and importantly, even descriptive norms that people explicitly reject have been found to still lead many of them to behaviorally and cognitively conform: "explicit egalitarians" reminded of the descriptive norm that men are more likely to be leaders than women were subsequently less likely to treat a woman seated at the head of a table as the group leader than a man in the same position (Peters, 2020, p. 17; Porter \& Geis, 1981, p. 52). Finally, studies suggest that even when they learn about descriptive norms in other individuals' groups and these norms capture morally problematic

2) Notice that there are different notions of descriptive norms in the literature. For instance, Bicchieri (2017) defines them as "a pattern of behavior such that individuals prefer to conform to it on condition that they believe that most people in their reference network conform to it” (p. 19). Here I adopt Cialdini et al.'s common notion.

3) Philosophers might balk at the use of the term 'norm' for these behavioral regularities. This is standard terminology in psychology, however, and I shall thus adopt it. 
behavior (e.g., making babies cry), people still often tend to expect members of those groups to conform, and are more accepting of individuals displaying the problematic behavior in such a group than in another group where the behavior is the same but not the norm (Roberts, Ho, \& Gelman, 2019, p. 382).

Having said that, descriptive norms do not always elicit conformist responses in all people and all domains (Paryavi et al., 2019; Richter, Thøgersen, \& Klöckner, 2018). Still, recent literature reviews (John et al., 2019) and several meta-analyses have found strong evidence of the predictive validity of descriptive norms in intention formation and behavior guidance across a wide range of domains (Melnyk et al., 2019; Rivis \& Sheeran, 2003). Moreover, descriptive norms turn out to be significantly more effective than prescriptive norms (Melnyk et al., 2019).

There is a particularly powerful type of descriptive norm that will be relevant below. Notice first that some kinds of descriptive norms are not only about prevalent features among people, but also about collective increases of these features in a population (Sparkman \& Walton, 2017). An example would be a norm expressed in a claim such as 'Increasingly more people have smartphones'. Generalizations about collective increases in a particular characteristic or behavior in a population (which might be a minority) have been called 'dynamic norms' (Mortensen et al., 2019; Sparkman \& Walton, 2017). Dynamic norms pertaining to majority trends can be viewed as a subset of descriptive norms because they refer to features most people increasingly exhibit. I shall call norms that refer only to majority features without also indicating trends static descriptive norms. And I will call norms that refer to majority or minority features while also indicating trend information dynamic descriptive norms.

Studies suggest that dynamic descriptive norms can have a stronger impact on behavior than static descriptive norms both when the two norms push in different directions or in the same. For instance, in a naturalistic setting, when Sparkman and Walton (2017) told lunch goers that a growing minority is making an effort to limit their meat consumption, this doubled the percentage of people who bought lunch without meat, as compared with a static descriptive norm condition and a control condition. Similarly, when Sparkman and Walton equipped some washing machines in college laundries with a message indicating that students are changing, with most now using full loads, they found that students used these machines $29 \%$ less over the next three weeks (compared to the preceding three weeks). Machines displaying only the static descriptive norm that most students do their laundry with full loads were used only $10 \%$ less. Other studies focusing on other behaviors have since independently confirmed the more pronounced efficacy of trend capturing dynamic norms (see Loschelder et al., 2019; Mortensen et al., 2019).

Since descriptive norms, in general, have been found to have significant effects on behavior and cognition (e.g., stereotyping, intention formation, etc., Duguid \& Thomas-Hunt, 2015; Rivis \& Sheeran, 2003) that are often stronger than those of prescriptive norms (Melnyk et al., 2019), it is unsurprising that they have been explored in research on how to tackle various social problems (e.g., environmentally unfriendly behavior, etc., Lede \& Meleady, 2019; Sparkman \& Walton, 2019). However, descriptive norms have not yet been related to the specific issue of political polarization and polarization claims.

\section{Polarization Claims Convey Descriptive Norms}

As noted above, polarization claims often involve generalizations indicating what socially undesirable behavioral and/or cognitive features most people in a particular group (e.g., people in the U.S. and Europe, 'ordinary Americans', liberals, etc.) have. This means that due to their genericity, polarization claims often communicate descriptive norms. In fact, since polarization claims often displays not only genericity but also dynamicity, they often convey dynamic descriptive norms, namely norms about what features members of particular political groups (e.g., people in the U.S. and Europe, liberals, etc.) commonly and increasingly more exhibit. That is, polarization claims often communicate norms that incline an audience to align their own behavior and information processing (e.g., stereotyping, disapproval, etc.; Duguid \& Thomas-Hunt, 2015) with these norms.

To make this more concrete, consider again the examples from Table 1. The preceding discussion provides reasons to assume that the statements in Table 1 incline at least some political opponents in the audience (e.g., people in the U.S./Europe, 'ordinary Americans', the British public, liberals, European partisans, etc.) to become more polarized, increase their dislike and distrust towards their political opponents, become more unwilling to live near them, view their 
ideas as misguided, become more ready to believe that their country is divided over politics, feel pessimistic about a change of this situation, and so on. The support for these assumptions comes from the studies mentioned earlier which suggest that descriptive norms, particularly, dynamic descriptive norms, tend to prompt people to conform in their behavior and attitudes even when the norms capture negative features (e.g., unhealthy eating, stereotyping, stealing, corruption, etc., Cialdini et al., 2006; Duguid \& Thomas-Hunt, 2015; Köbis et al., 2015; Staunton et al., 2014).

There is other experimental work that can be viewed as lending support to the view that polarization claims themselves are likely to have polarizing effects. For instance, Levendusky and Malhotra (2016a) had their study participants (U.S. Democrats and Republicans) read one of three newspaper articles: an article describing the electorate as deeply polarized, an article depicting the electorate as moderate, and a non-political article. Afterwards, participants were asked questions measuring (inter alia) their own affective polarization (e.g., via their ratings of the other party on a 'feeling thermometer', listing things they disliked about the other party, or reporting how comfortable they are having friends voting for the opposite party). In their responses, participants exposed to depictions of a polarized electorate subsequently displayed more affective polarization. Levendusky and Malhotra do not consider descriptive norms yet. But their findings are as expected if the above proposal on how polarization claims might increase political polarization is correct. According to that proposal, when the study participants read that the electorate is divided, they learned about a descriptive norm capturing polarization among Democrats and Republicans that they then conformed to (Democrat vs. Republican subjects differently), resulting in an increase in their own affective polarization.

To further corroborate the proposal that polarization claims might fuel political polarization, notice too that these claims are widely broadcast by authoritative sources (in the media, newspapers, TV, etc.) and typically refer to very large demographic groups (e.g., U.S. citizens, European partisans etc.). This does not only mean that recipients of polarization claims are frequently in the reference set of the claims and likely to readily believe them (due to their authoritative source). It also raises the prospect that the descriptive norms indicated by polarization claims might additionally drive individuals who are still politically neutral or moderate to take up a position politically, or become more extreme, respectively.

Having said that, the extent to which people are influenced by descriptive norms is likely to depend on the extent to which they self-identify with the group at issue in the norms. For studies found that group norms about a certain behavior (e.g., regular exercise) influenced people's intention to act in line with a group's norms "only in subjects who identified strongly with the group" (Terry \& Hogg, 1996, p. 195). The effects of descriptive norms captured in polarization claims are thus likely to be a function of the degree to which the person identifies with her political identity. The claims' contribution to further polarization should hence be more pronounced for individuals who more strongly identify with the group at issue (e.g., the political 'extremes' on both sides).

Indeed, in research on social norms, social identity is thought be tied to group properties and behavioral standards such that strong self-identifiers perceive a lack of conformity to group norms as a "threat to the legitimacy of the group. Self-categorization accentuates the similarities between one's behavior and that prescribed by the group norm, thus causing conformity as well as the disposition to control and punish transgressors" (Bicchieri, Muldoon, \& Sontuoso, 2018). That is, strong self-identifiers are not only much more likely to conform to the group's descriptive norms but also to make efforts to ensure other group members do so too. Descriptive norms and their effects on behavior can thus be viewed as properties of groups and social identities.

It should be noted too, though, that some of the studies mentioned above (e.g., Roberts et al., 2019) suggest that even when it comes to people who do not identify with the group mentioned in polarization claims (e.g., politically neutral individuals), upon exposure to these claims, these individuals too are likely to expect members of the groups who are at issue (e.g., liberals, Republicans, Europe partisans, etc.) to act in norm-consistent ways. And these expectations can bias their social interactions with the targets. For instance, if you expect someone to be politically polarized, then that might lead you to act in a more aloof way toward her, potentially causing her, in turn, to become hostile toward you (Bicchieri, 2017, p. 135; Stinson et al., 2009), which increases social division.

Finally, as Iyengar et al. (2019) emphasize, unlike with respect to race, gender, and other social divides where group-related attitudes and behaviors are subject to social norms of civility and tolerance, there are no corresponding social "pressures to temper disapproval of political opponents. If anything, the rhetoric and actions of political leaders demonstrate that hostility directed at the opposition is acceptable and often appropriate" (p. 133). If hostility toward 
political opponents is socially tolerated and often appropriate, and if people learn that this hostility is widespread, this might also make them feel relieved of responsibility for it, unleashing political aversion even further (a phenomenon related to the 'moral licensing effect'; Blanken, van de Ven, \& Zeelenberg, 2015). In sum, there are good grounds to believe that polarization claims are likely to fuel political polarization via the impact of descriptive norms on people's behavior and information processing.

\section{The Silver Lining, or Unexplored Ways of Tackling Political Polarization}

Since political polarization drives people apart, it is clearly socially harmful (McCoy et al., 2018; Sunstein, 2009; Talisse, 2019). It thus becomes important to explore possible strategies of reducing it. I want to suggest that while people's tendency to conform to descriptive norms, particularly dynamic norms, can lead them to respond to polarization claims in ways exacerbating political polarization, the same tendency also provides the basis for potential interventions to reduce it. These interventions are experimentally testable but have so far not been considered in the psychological and political science literature. I shall outline three.

\section{Recycling Dynamic Norms}

Dynamic norms have been found to be stronger than static descriptive norms in eliciting conformity no matter whether they capture minority trends (e.g., 'increasingly more people limit their meat consumption, but most still eat too much meat') or majority trends (e.g., 'increasingly more students conserve water when doing their laundry; most already do so') (Mortensen et al., 2019; Sparkman \& Walton, 2017). Indeed, when Mortensen et al. (2019) told a group of students that only $48 \%$ of their fellows engaged in water conservation behavior but that this figure had increased from $37 \%$ two years before, these students themselves subsequently displayed more water conservation behavior than controls and students only presented with the minority norm. The dynamic framing 'buffered' the detrimental effect of the minority norm, which indirectly conveyed a negative descriptive norm (i.e., that most students do not conserve water).

If we apply these points to polarization claims, then communicating dynamic norms capturing minority trends about political polarization might help reduce it. For instance, there is evidence that an increasing minority of the U.S. population worries about, and are willing to tackle, political polarization (Parker et al., 2019). Given this, consider the following rephrasing of polarization claim (6) from Table 1: 'U.S. citizens are more inclined than ever to regard the ideas of their political opponents as misguided and a significant threat to the well-being of the nation, but a growing minority of them make an effort to moderate their views about the ideas of their political opponents.' If minority trend information can weaken the detrimental effect of negative static descriptive norms (Mortensen et al., 2019), then polarization claims of this type hold the potential to decrease political polarization.

\section{Acknowledging Variations in the Data}

To reduce the likelihood that polarization claims fuel political polarization, those communicating about the latter might also add explicit scope-restricting quantifiers such as 'some' or 'many' when describing members of groups. Such scope restrictions can undercut an audience's generalization of the claims to all or most members of a group, which lowers the probability that the claims transmit descriptive norms.

Granted, when the quantifiers needed in the polarization claims so as to accurately describe groups are 'most' or 'all' then the same problem as before will arise. But, even though it is often suggested that political polarization is pervasive and increasing, several studies indicate that this might be an exaggeration (Cavari \& Freedman, 2018; Tappin \& McKay, 2019; Westwood, Peterson, \& Lelkes, 2019). For instance, in experiments with more than 6000 people, Klar et al. (2018) found that although some Americans are indeed affectively polarized, many "more simply want to avoid talking about politics. In fact, many people do not want [e.g.] their child to marry someone [even] from their own party if that hypothetical in-law were to discuss politics frequently" (p. 379). Klar et al.'s and other surveys suggest that only about $20 \%$ of U.S. Americans are truly affectively polarized (for references, see Klar et al., 2019). Yet, about 90\% U.S. Americans 
believe their country is divided over politics (Heltzel \& Laurin, 2020, p. 179). They perceive much more polarization than actually exists (Levendusky \& Malhotra, 2016b).

This is an instance of a well-documented phenomenon known as "false polarization": people tend to overestimate the extent of polarization between their in-group vs. out-groups (Pronin, Puccio, \& Ross, 2002). Relatedly, studies found that when it comes to their perceptions of, say, how many people dismiss anthropogenic climate change, people tend to "grossly overestimate the numbers" (Leviston, Walker, \& Morwinski, 2013, p. 334) and display "pluralistic ignorance", a phenomenon occurring when most individuals privately reject a view but falsely believe that most others endorse it (Prentice \& Miller, 1996). Crucially, research suggests that when people believe most others dismiss/accept climate change, this can make them become less/more likely to believe in it themselves (Goldberg et al., 2020). These points provide reasons to suspect that the broad generalizations in polarization claims concerning the actual distribution of polarization might often be exaggerated too and can thus perhaps frequently be replaced with more restricted quantified claims (involving, e.g., 'some' or 'many') without becoming inaccurate.

Additionally, communicating that the vast majority of people overall (i.e., independently of political identity) is in fact not aversive against their political opponents can help decrease political polarization too. For, as mentioned above, people's tendency to conform to descriptive norms of an overall population has been found to out-power even the common political in-group vs. out-group (e.g., Republican vs. Democrat) mentality (Pryor et al., 2019).

In this context, it is worth noting that some researchers who aim to correct misperceptions about the pervasiveness of political polarization do so by using polarization claims to the effect that people only widely believe that polarization is common (see, e.g., Klar et al., 2019). Yet, this too is perhaps problematic, as such claims themselves are likely to convey descriptive norms, namely about what people commonly believe. Assuming that the preceding argument is correct, this means that these claims too can have a negative consequence. They can contribute to the proliferation of the (arguably inaccurate) belief that political polarization is very common. This helps underline the relevance of acknowledging variations in the data even when it comes to reports on people's mere perception of political polarization.

Finally, the strategy of noting variations also coheres well with and can be further motivated by research on intergroup conflict resolution. Studies in that area of work suggest that perception of out-group homogeneity, i.e., the view that members of an out-group are all alike, is common in inter-group conflicts and a significant hindrance to inter-group reconciliation (Lederach, 1997). Increasing the perceived diversity of an out-group has been found to decrease levels of generalized negative beliefs about the out-group and to significantly boost in-group members' openness to the out-group's views (Čehajić-Clancy et al., 2016). Since an explicit acknowledgement of variation in the data on polarization (e.g., only some U.S. white, middle-class conservatives genuinely increasingly dislike liberals) may facilitate an audience's perception of diversity in political out-groups (e.g., conservatives), this point lends independent support to adopting the strategy at issue.

\section{Utilizing Negativity}

To introduce a final suggestion on how to reduce political polarization via descriptive norms, consider a study by Bergquist and Nilsson (2019). It involved descriptive norms containing negations, i.e., "descriptive don't-norms", which pertained to, e.g., environmentally friendly action such as choosing an energy-efficient light bulb vs. avoiding an energy-inefficient one. Bergquist and Nilsson found these norms to be stronger in eliciting conformity than descriptive norms without negations. This is plausibly explained by the fact that survival requires more urgent attention to possible bad outcomes, which are indirectly captured in what most people do not do or try to avoid, than to good outcomes (Baumeister et al., 2001; Bergquist \& Nilsson, 2019).

Suppose we combine this point with the preceding consideration that in fact only a minority of, e.g., U.S. citizens is strongly affectively polarized and most of them are not (Klar et al., 2019). Consider the following statement rephrasing claim (6) from Table 1: 'While many U.S. citizens are more inclined than ever to regard the ideas of their political opponents as misguided and a significant threat to the well-being of the nation, overall, most of them do not do so and try to avoid excessive antipathy towards the ideas of their political opponents.' If people are more sensitive and responsive to descriptive don't-norms, then statements of this kind should offer another way to counteract political polarization. 


\section{Limitations}

The proposals and arguments introduced in this paper draw on data from various psychological studies on descriptive norms. The data pertain to other phenomena than political polarization and so do not offer direct support for the points made here. So far, there is no experimental study directly testing the effects of descriptive norms in the context of polarization claims. Indeed, while descriptive norms have recently been investigated in some politically relevant domains (e.g., voting behavior or policy activism; Gerber \& Rogers, 2009; Hassell \& Wyler, 2019) and with respect to different political in-group vs. out-group orientations (Pryor et al., 2019), there is yet no mentioning of descriptive norms in the literature on political polarization, in particular.

While the reliance on data from other studies is a limitation of the preceding discussion, the mentioned findings on descriptive norms come from studies covering a very wide range of different domains, and we have little reason to assume that the domain of polarization claims is an outlier in the here relevant respects. Since that is so, it would be surprising if in the context of polarization claims, the conformity effects discussed did not occur at all. While future empirical testing might show otherwise, for now, the studies mentioned lend indirect support to the proposals and overall argument offered here. The paper achieves its goal if it prompts experimental investigations of the connections between descriptive norms, polarization claims, and political polarization.

\section{Conclusion}

Scholars working on political polarization, including political psychologists, have not yet considered the implications of studies on descriptive norms for their own theorizing. Similarly, psychologists working on social norms and investigating descriptive norms have not yet explored the issue of political polarization. The two areas of research, i.e., the work on political polarization and the work on descriptive norms, have here been connected. The main upshot is disconcerting: there is reason to believe that many claims about political polarization in journal articles, at conferences, in the media, etc. display features (genericity and dynamicity) in virtue of which they convey a particular kind of descriptive norms that frequently incline people to align their behavior, cognition, and affective dispositions to these norms. Since polarization claims capture generalizations linking political groups with negative features (e.g., antipathy, closed-mindedness, hostility, etc.), the resulting conformity effects are socially detrimental, fueling political polarization.

I noted, however, that there is a silver lining. The process underlying the problematic effects at issue also offers a basis for developing ways of counteracting political polarization that have so far not been explored in the literature. I proposed three that involve re-formulations of polarization claims. Since political polarization has been shown to be at the heart of some of the currently most pressing social problems (e.g., political hatred, science skepticism, climate change denial, and tackling COVID-19; Goldberg et al., 2020; Hart et al., 2020; Mason, 2018a; Nisbet, Cooper, \& Garrett, 2015), the proposals outlined above introduce an important area for future experimental investigations. ${ }^{4}$

Funding: The research for this paper was partly funded by the Danmarks Frie Forskningsfond Grant no: 8018-00053B.

Competing Interests: The author has declared that no competing interests exist.

Acknowledgments: Many thanks for helpful comments on earlier drafts to Mikkel Gerken, Nikolaj Nottelmann, and Ken Boyd. I'm also indebted to Dan Kelly for introducing me to the research on descriptive norms some years ago.

4) The argument proposed here also raises many normative, philosophically interesting questions related to the ethics of science communication. For instance, to what extent do the points made here with respect to polarization claims also hold for other kinds of social scientific claims found in communication between scientists and the public? And do scientists have a moral responsibility for the kind of effects discussed? I explore these questions elsewhere Peters (in press). 


\section{References}

Baumeister, R., Bratslavsky, E., Finkenauer, C., \& Vohs, K. (2001). Bad is stronger than good. Review of General Psychology, 5, 323-370. https://doi.org/10.1037/1089-2680.5.4.323

Becker, J., Porter, E., \& Centola, D. (2019). The wisdom of partisan crowds. Proceedings of the National Academy of Sciences of the United States of America, 116(22), 10717-10722. https://doi.org/10.1073/pnas.1817195116

Bergquist, M., \& Nilsson, A. (2019). The DOs and DON'Ts in social norms: A descriptive don't-norm increases conformity. Fournal of Theoretical Social Psychology, 3, 158-166. https://doi.org/10.1002/jts5.43

Bicchieri, C. (2017). Norms in the wild: How to diagnose, measure, and change social norms. New York, NY, USA: Oxford University Press.

Bicchieri, C., Muldoon, R., \& Sontuoso, A. (2018). Social norms. In Edward N. Zalta (Ed.), The Stanford encyclopedia of philosophy. Retrieved from https://plato.stanford.edu/archives/win2018/entries/social-norms

Bishop, B. (2009). The big short: Why the clustering of like-minded America is tearing us apart. New York, NY, USA: Harcourt Publishing Co.

Blanken, I., van de Ven, N., \& Zeelenberg, M. (2015). A meta-analytic review of moral licensing. Personality and Social Psychology Bulletin, 41, 540-558. https://doi.org/10.1177/0146167215572134

Brick, C., \& van der Linden, S. L. (2018, June). How identity, not issues, explains the partisan divide. Scientific American - Mind. Retrieved from https://www.scientificamerican.com/article/how-identity-not-issues-explains-the-partisan-divide

Carothers, T., \& O'Donohue, A. (2019). Democracies divided: The global challenge of political polarization. Washington, DC, USA: Brookings Institution Press.

Cavari, A., \& Freedman, G. (2018). Polarized mass or polarized few? Assessing the parallel rise of survey nonresponse and measures of polarization. The fournal of Politics, 80(2), 719-725. https://doi.org/10.1086/695853

Čehajić-Clancy, S., Goldenberg, A., Gross, J. J., \& Halperin, E. (2016). Social-psychological interventions for intergroup reconciliation: An emotion regulation perspective. Psychological Inquiry, 27(2), 73-88. https://doi.org/10.1080/1047840X.2016.1153945

Cialdini, R. B. (2003). Crafting normative messages to protect the environment. Current Directions in Psychological Science, 12(4), 105-109. https://doi.org/10.1111/1467-8721.01242

Cialdini, R. B., Demaine, L. J., Sagarin, B. J., Barrett, D. W., Rhoads, K., \& Winter, P. L. (2006). Managing social norms for persuasive impact. Social Influence, 1(1), 3-15. https://doi.org/10.1080/15534510500181459

Cialdini, R. B., Reno, R. R., \& Kallgren, C. A. (1990). A focus theory of normative conduct: Recycling the concept of norms to reduce littering in public places. Journal of Personality and Social Psychology, 58(6), 1015-1026. https://doi.org/10.1037/0022-3514.58.6.1015

Cimpian, A., Brandone, A., \& Gelman, S. (2010). Generic statements require little evidence for acceptance but have powerful implications. Cognitive Science, 34, 1452-1482. https://doi.org/10.1111/j.1551-6709.2010.01126.x

Coffman, L. C., Featherstone, C. R., \& Kessler, J. B. (2017). Can social information affect what job you choose and keep? American Economic fournal: Applied Economics, 9(1), 96-117. https://doi.org/10.1257/app.20140468

Duguid, M. M., \& Thomas-Hunt, M. C. (2015). Condoning stereotyping? How awareness of stereotyping prevalence impacts expression of stereotypes. Fournal of Applied Psychology, 100, 343-359. https://doi.org/10.1037/a0037908

Gerber, A., \& Rogers, T. (2009). Descriptive social norms and motivation to vote: Everybody's voting and so should you. The fournal of Politics, 71, 178-191. https://doi.org/10.1017/S0022381608090117

Gerken, M. (2018). Expert trespassing testimony and the ethics of science communication. Fournal for General Philosophy of Science, 49, 299-318. https://doi.org/10.1007/s10838-018-9416-1

Goldberg, M. H., van der Linden, S., Leiserowitz, A., \& Maibach, E. (2020). Perceived social consensus can reduce ideological biases on climate change. Environment and Behavior, 52(5), 495-517. https://doi.org/10.1177/0013916519853302

Goldstein, N. J., Cialdini, R. B., \& Griskevicius, V. (2008). A room with a viewpoint: Using social norms to motivate environmental conservation in hotels. Journal of Consumer Research, 35, 472-482. https://doi.org/10.1086/586910

Hallsworth, M., List, J. A., Metcalfe, R. D., \& Vlaev, I. (2017). The behavioralist as tax collector: Using natural field experiments to enhance tax compliance. Fournal of Public Economics, 148, 14-31. https://doi.org/10.1016/j.jpubeco.2017.02.003

Hart, P. S., Chinn, S., \& Soroka, S. (2020). Politicization and polarization in COVID-19 news coverage. Science Communication, 42(5), 679-697. https://doi.org/10.1177/1075547020950735 
Hassell, H. J. G., \& Wyler, E. E. (2019). Negative descriptive social norms and political action: People aren't acting, so you should. Political Behavior, 41, 231-256. https://doi.org/10.1007/s11109-018-9450-z

Heltzel, G., \& Laurin, K. (2020). Polarization in America: Two possible futures. Current Opinion in Behavioral Sciences, 34, $179-184$. https://doi.org/10.1016/j.cobeha.2020.03.008

Iyengar, S., Lelkes, Y., Levendusky, M., Malhotra, N., \& Westwood, S. (2019). The origins and consequences of affective polarization in the United States. Annual Review of Political Science, 22, 129-146. https://doi.org/10.1146/annurev-polisci-051117-073034

Iyengar, S., \& Massey, D. S. (2019). Scientific communication in a post-truth society. Proceedings of the National Academy of Sciences of the United States of America, 116(16), 7656-7661. https://doi.org/10.1073/pnas.1805868115

John, P., Sanders, M., \& Wang, J. (2019). A panacea for improving citizen behaviors? Introduction to the symposium on the use of social norms in public administration. fournal of Behavioral Public Administration, 2(2). https://doi.org/10.30636/jbpa.22.119

Klar, S., Krupnikov, Y., \& Ryan, J. (2018). Affective polarization or partisan disdain? Untangling a dislike for the opposing party from a dislike of partisanship. Public Opinion Quarterly, 82(2), 379-390. https://doi.org/10.1093/poq/nfy014

Klar, S., Krupnikov, Y., \& Ryan, J. (2019, April 12). Is America hopelessly polarized, or just allergic to politics? New York Times. Retrieved from https:/www.nytimes.com/2019/04/12/opinion/polarization-politics-democrats-republicans.html

Köbis, N. C., van Prooijen, J. W., Righetti, F., \& Van Lange, P. A. (2015). 'Who doesn't?’ The impact of descriptive norms on corruption. PLoS One, 10(6), Article e0131830. https://doi.org/10.1371/journal.pone.0131830

Lede, E., \& Meleady, R. (2019). Applying social influence insights to encourage climate resilient domestic water behavior: Bridging the theory-practice gap. Wiley Interdisciplinary Reviews: Climate Change, 10(1), Article e562. https://doi.org/10.1002/wcc.562

Lederach, J. P. (1997). Building peace: Sustainable reconciliation in divided societies. Washington, DC, USA: United States Institute of Peace Press.

Levendusky, M. S., \& Malhotra, N. (2016a). Does media coverage of partisan polarization affect political attitudes? Political Communication, 33(2), 283-301. https://doi.org/10.1080/10584609.2015.1038455

Levendusky, M. S., \& Malhotra, N. (2016b). (Mis)perceptions of partisan polarization in the American public. Public Opinion Quarterly, 80(S1), 378-391. https://doi.org/10.1093/poq/nfv045

Leviston, Z., Walker, I., \& Morwinski, S. (2013). Your opinion on climate change might not be as common as you think. Nature Climate Change, 3(4), 334-337. https://doi.org/10.1038/nclimate1743

Loschelder, D. D., Siepelmeyer, H., Fischer, D., \& Rubel, J. A. (2019). Dynamic norms drive sustainable consumption: Norm-based nudging helps café customers to avoid disposable to-go-cups. Fournal of Economic Psychology, 75(Part A), Article 102146. https://doi.org/10.1016/j.joep.2019.02.002

Maher, P., Igou, E., \& van Tilburg, W. (2018). Brexit, Trump, and the polarizing effect of disillusionment. Social Psychological \& Personality Science, 9(2), 205-213. https://doi.org/10.1177/1948550617750737

Mason, L. (2018a). Uncivil agreement: How politics became our identity. Chicago, IL, USA: University of Chicago Press.

Mason, L. (2018b). Ideologues without issues: The polarizing consequences of ideological identities. Public Opinion Quarterly, 82(S1), 866-887. https://doi.org/10.1093/poq/nfy005

McCoy, J., Tahmina, R., \& Somer, M. (2018). Polarization and the global crisis of democracy: Common patterns, dynamics, and pernicious consequences for democratic polities. American Behavioral Scientist, 62(1), 16-42. https://doi.org/10.1177/0002764218759576

Melnyk, V., Van Herpen, E., Jak, S., \& Van Trijp, H. (2019). The mechanisms of social norms' influence on consumer decision making: A meta-analysis. Zeitschrift für Psychologie, 227(1), 4-17. https://doi.org/10.1027/2151-2604/a000352

Mortensen, C. R., Neel, R., Cialdini, R. B., Jaeger, C. M., Jacobson, R. P., \& Ringel, M. (2019). Trending norms: A lever for encouraging behaviors performed by the minority. Social Psychological \& Personality Science, 10(2), 201-210. https://doi.org/10.1177/1948550617734615

Nisbet, E. C., Cooper, K. E., \& Garrett, R. K. (2015). The partisan brain: How dissonant science messages lead conservatives and liberals to (dis)trust science. The Annals of the American Academy of Political and Social Science, 658(1), 36-66. https://doi.org/10.1177/0002716214555474

Parker, K., Morin, R., \& Horowitz, J. (2019, March 21). Looking to the future, public sees an America in decline on many fronts. Pew Research Centre. Retrieved from https://www.pewsocialtrends.org/2019/03/21/public-sees-an-america-in-decline-on-many-fronts

Paryavi, M., Bohnet, I., \& van Geen, A. (2019). Descriptive norms and gender diversity: Reactance from men. fournal of Behavioral Public Administration, 2(1). https://doi.org/10.30636/jbpa.21.51 
Peters, U. (2020). An argument for egalitarian confirmation bias and against political diversity in academia. Synthese. Advance online publication. https://doi.org/10.1007/s11229-020-02846-2

Peters, U. (in press). Science communication and the problematic impact of descriptive norms. British fournal for the Philosophy of Science. Draft retrieved from https://philpapers.org/archive/PETSCA-5.pdf

Porter, N., \& Geis, F. L. (1981). Women and nonverbal leadership cues: When seeing is not believing. In C. Mayo \& N. Henley (Eds.), Gender, androgyny, and nonverbal behavior (pp. 39-61). New York, NY, USA: Springer.

Prentice, D. A. (2007). Prescriptive vs. descriptive norms. In R. Baumeister \& K. Vohs (Eds.), Encyclopedia of social psychology (pp. 629-630). Thousand Oaks, CA, USA: SAGE.

Prentice, D. A., \& Miller, D. T. (1996). Pluralistic ignorance and the perpetuation of social norms by unwitting actors. In M. P. Zanna (Ed.), Advances in experimental social psychology (pp. 161-209). Academic Press. https://doi.org/10.1016/S0065-2601(08)60238-5

Pronin, E., Puccio, C., \& Ross, L. (2002). Understanding misunderstanding: Social psychological perspectives. In T. Gilovich, D. Griffin, \& D. Kahneman (Eds.), Heuristics and biases: The psychology of intuitive judgment (pp. 636-665). Cambridge, United Kingdom: Cambridge University Press.

Pryor, C., Perfors, A., \& Howe, P. (2019). Conformity to the descriptive norms of people with opposing political or social beliefs. PLoS One, 14(7), Article e0219464. https://doi.org/10.1371/journal.pone.0219464

Reiljan, A. (2020). 'Fear and loathing across party lines' (also) in Europe: Affective polarisation in European party systems. European Journal of Political Research, 59, 376-396. https://doi.org/10.1111/1475-6765.12351

Richter, I., Thøgersen, J., \& Klöckner, C. A. (2018). A social norms intervention going wrong: Boomerang effects from descriptive norms information. Sustainability, 10, Article 2848. https://doi.org/10.3390/su10082848

Rivis, A., \& Sheeran, P. (2003). Descriptive norms as an additional predictor in the theory of planned behaviour: A meta-analysis. Current Psychology, 22, 218-233. https://doi.org/10.1007/s12144-003-1018-2

Roberts, S. O., Ho, A. K., \& Gelman, S. A. (2019). The role of group norms in evaluating uncommon and negative behaviors. fournal of Experimental Psychology: General, 148, 374-387. https://doi.org/10.1037/xge0000534

Schultz, P. W., Nolan, J. M., Cialdini, R. B., Goldstein, N. J., \& Griskevicius, V. (2007). The constructive, destructive, and reconstructive power of social norms. Psychological Science, 18(5), 429-434. https://doi.org/10.1111/j.1467-9280.2007.01917.x

Shackle, S. (2019, May 27). European elections expose polarized British public. Deutsche Welle. Retrieved from https://www.dw.com/en/european-elections-expose-polarized-british-public/a-48904801

Shi, F., Teplitskiy, M., Duede, E., \& Evans, J. (2019). The wisdom of polarized crowds. Nature Human Behaviour, 3, 329-336. https://doi.org/10.1038/s41562-019-0541-6

Sparkman, G., \& Walton, G. M. (2017). Dynamic norms promote sustainable behavior, even if it is counter-normative. Psychological Science, 28, 1663-1674. https://doi.org/10.1177/0956797617719950

Sparkman, G., \& Walton, G. M. (2019). Witnessing change: Dynamic norms help resolve diverse barriers to personal change. fournal of Experimental Social Psychology, 82, 238-252. https://doi.org/10.1016/j.jesp.2019.01.007

Staunton, M., Louis, W. R., Smith, J. R., Terry, D. J., \& McDonald, R. I. (2014). How negative descriptive norms for healthy eating undermine the effects of positive injunctive norms. fournal of Applied Social Psychology, 44(4), 319-330.

https://doi.org/10.1111/jasp.12223

Stinson, D. A., Cameron, J. J., Wood, J. V., Gaucher, G., \& Holmes, J. G. (2009). Deconstructing the 'reign of error': Interpersonal warmth explains the self-fulfilling prophecy of anticipated acceptance. Personality and Social Psychology Bulletin, 35, $1165-1178$. https://doi.org/10.1177/0146167209338629

Sunstein, C. (2009). Going to the extreme. Oxford, United Kingdom: Oxford University Press.

Talisse, R. (2019). Overdoing democracy: Why we must put politics in its place. Oxford, United Kingdom: Oxford University Press.

Tappin, B. M., \& McKay, R. T. (2019). Moral polarization and out-party hostility in the US political context. fournal of Social and Political Psychology, 7(1), 213-245. https://doi.org/10.5964/jspp.v7i1.1090

Terry, D. J., \& Hogg, M. A. (1996). Group norms and the attitude-behavior relationship: A role for group identification. Personality and Social Psychology Bulletin, 22(8), 776-793. https://doi.org/10.1177/0146167296228002

Van Boven, L., Ehret, P. J., \& Sherman, D. K. (2018). Psychological barriers to bipartisan public support for climate policy. Perspectives on Psychological Science, 13, 492-507. https://doi.org/10.1177/1745691617748966

Webster, S., \& Abramowitz, A. (2017). The ideological foundations of affective polarization in the U.S. electorate. American Politics Research, 45(4), 621-647. https://doi.org/10.1177/1532673X17703132 
Westwood, S. J., Peterson, E., \& Lelkes, Y. (2019). Are there still limits on partisan prejudice? Public Opinion Quarterly, 83, 584-597. https://doi.org/10.1093/poq/nfz034 